\title{
Prognostic factors for overall survival in patients with primary duodenal adenocarcinoma
}

\author{
Teng-Yan Li, Qi-Chen Chen, Hong Zhao, Ye-Fan Zhang, Jian-Jun Zhao, Jian-Qiang Cai \\ Department of Hepatobiliary Surgery, National Cancer Center/National Clinical Research Center for Cancer/Cancer Hospital, Chinese Academy of \\ Medical Sciences and Peking Union Medical College, Beijing, China \\ Contributions: (I) Conception and design: TY Li; (II) Administrative support: Z Hong, JQ Cai; (III) Provision of study materials or patients: All \\ authors; (IV) Collection and assembly of data: TY Li; (V) Data analysis and interpretation: TY Li, QC Chen; (VI) Manuscript writing: All authors; (VII) \\ Final approval of manuscript: All authors. \\ Correspondence to: Jian-Qiang Cai. Department of Hepatobiliary Surgery, National Cancer Center/National Clinical Research Center for Cancer/ \\ Cancer Hospital, Chinese Academy of Medical Sciences and Peking Union Medical College, No. 17 Nanli, Panjiayuan, Chaoyang District, Beijing \\ 100021, China. Email: caijianqiang188@sina.com.
}

Background The complete resection of primary duodenal adenocarcinoma (PDA) offers a chance for a cure, but the clinical and pathological characteristics of survivors have not been well studied.

Methods: Patients with stage I-III PDA who underwent surgical resection between 2013 and 2018 were identified retrospectively and followed until December 2019. All patients are from the Cancer Hospital Chinese Academy of Medical Sciences. The clinical and pathological information of the patients, such as age, gender, tumor location, operative procedure, pathologic features, TNM stage, common presenting symptoms, lymph node dissection status, serum tumor markers, etc., was collected in detail. The KaplanMeier method and a Cox proportional hazards model were used for the survival analysis.

Results: In total, 85 patients with PDA were eligible for this study. Among these patients, 48 were male $(56.5 \%), 37$ were female (43.5\%), the median age was 59 (range, 22-79) years, $44(51.8 \%)$ patients were aged $<60$ years, and $41(48.2 \%)$ patients were aged $\geq 60$ years. The $1-, 3-$, and 5 -year survival rates were $93.7 \%$, $79.4 \%$, and $64.9 \%$, respectively. The median overall survival (OS) was 27 months (range, 2-82 months), and the median follow-up was 27 months (range, 3-82 months). The patients with stage III disease had the worst prognosis $(\mathrm{P}=0.001)$. The univariate analysis showed that lymph node positivity $(\mathrm{P}=0.000)$, the $\mathrm{N}$ stage $(\mathrm{P}=0.000)$, the TNM stage $(\mathrm{P}=0.001)$ and carbohydrate antigen 19-9 (CA19-9) positivity $(\mathrm{P}=0.038)$ were related to $\mathrm{OS}$. However, the total number of lymph nodes $(\mathrm{LN})$ retrieved $(\mathrm{P}=0.723)$, tumor differentiation $(\mathrm{P}=0.136)$, carcinoembryonic antigen $(\mathrm{CEA})(\mathrm{P}=0.812)$, gender $(\mathrm{P}=0.477)$, operation type $(\mathrm{P}=0.860)$, tumor size $(\mathrm{P}=0.869)$, tumor site $(\mathrm{P}=0.120)$, age $(\mathrm{P}=0.733)$, intraoperative blood loss $(\mathrm{P}=0.660)$, and intraoperative blood transfusion $(\mathrm{P}=0.748)$ were not correlated with $\mathrm{OS}$. The multivariate analysis suggested that the lymph node status was an independent prognostic risk factor for OS.

Conclusions: In our study the median OS was 27 months (range, 2-82 months), and the 5-year survival rates was $64.9 \%$. The lymph node status was the only prognostic factor for OS in PDA.

Keywords: Primary duodenal adenocarcinoma (PDA); clinical features; overall survival; prognostic factors

Submitted Jun 19, 2020. Accepted for publication Dec 08, 2020.

doi: 10.21037/apm-20-1280

View this article at: http://dx.doi.org/10.21037/apm-20-1280

\section{Introduction}

Primary duodenal adenocarcinoma (PDA) is a rare malignant tumor that originates from the duodenal mucosal glandular epithelium. The diagnosis of duodenal adenocarcinoma should exclude malignant tumors of the ampulla of Vater, the lower end of the common bile duct 
and the head of the pancreas. Its incidence accounts for $0.05 \%$ of all malignant tumors and $0.5 \%$ of gastrointestinal tumors (1-3). Although considerable research has been performed, thus far, most studies were not well designed. Due to its low incidence, to date, there are no randomized controlled trials, and the number of cases in some studies was small, while other studies lacked pathological information and serum tumor markers. Our understanding of the natural history of and predictors of survival in PDA remains incomplete.

There is no international consensus regarding the best treatment strategy and prognosis of the disease. Some scholars believe that pancreaticoduodenectomy (PD) is applicable to all PDAs (4). However, other scholars believe that endoscopic mucosal resection (EMR) and endoscopic submucosal dissection (ESD) can be used as effective treatments (4-6). In Poultsides's (7) study, the overall survival (OS) rates at 5 years were $48 \%$, and the number of lymph nodes involved by metastasis decreased the 5 -year survival. In Cloyd's (5) study, the median OS was 38 months following simple resection (SR) and 29 months following radical resection (RR). The 5 -year OS rates were $41.3 \%$ following SR and 37.6 following $\mathrm{RR}(\mathrm{P}=0.89)$.

Several studies reported that the main factors predicting survival after resection of PDA were the tumor margin (8), tumor grade, presenting symptoms, lesion size, lymph node involvement and presence of metastases $(2,6,9)$. However, Poultsides et al. (7) reported that only lymph node metastasis was an independent predictor of OS. Given the controversy regarding the prognosis of PDA and surgical methods, we evaluated our institution's experience with these rare tumors. In this study, a retrospective study of 85 PDA patients was conducted to analyze their clinical characteristics and evaluate the factors that affect OS.

We present the following article in accordance with the STROBE reporting checklist (available at http://dx.doi. org/10.21037/apm-20-1280).

\section{Methods}

\section{Subjects}

The study was conducted in accordance with the Declaration of Helsinki (as revised in 2013). The study was approved by the Ethics Committee of the Cancer Hospital, Chinese Academy of Medical Sciences (ID: NCC2019C-016), and informed consent was taken from all the patients. The study population included patients from the Cancer Hospital Chinese Academy of Medical Sciences who were admitted between January 2013 and November 2018. Patients with adenocarcinoma arising from the ampulla of Vater were excluded.

\section{Measures and procedures}

Clinical data, such as the patients' demographics, presenting symptoms, preoperative levels of carcinoembryonic antigen (CEA) and carbohydrate antigen 19-9 (CA19-9), tumor location, tumor size, operation type, intraoperative blood loss, intraoperative blood transfusion, and pathologic stage, were reviewed, and pathologic data, including the histologic grade, $\mathrm{T}$ stage, $\mathrm{N}$ stage, nodal metastasis, and number of nodes involved and examined, were also reviewed. All information is summarized in Table 1. The TNM staging of the tumors was based on the 8th edition of the American Joint Committee on Cancer (AJCC) (in 2018).

\section{Outcomes}

The current vital status of the patients was determined from the medical records in the follow-up clinic or by telephone interviews with the patients or their family. OS was our outcome and defined as the period from the time of pathological diagnosis to the time of death or the last follow-up. The last follow-up date was November 20, 2019.

\section{Statistical analysis}

SPSS 23.0 software was used for the statistical analysis. The continuous variables are represented as the median (range). The Kaplan-Meier method was used to calculate the survival rate and draw the survival curves. The log rank test was used for the single factor analysis, and a Cox regression model was used for the multivariate analysis. $\mathrm{P}<0.05$ was considered statistically significant.

\section{Results}

\section{Patient cohort demographics}

In total, all 85 patients were confirmed by pathology to have PDA. All patients underwent R0 resection. Among these patients, 48 were male $(56.5 \%)$, and 37 were female $(43.5 \%)$. The median age was 59 years (range, $22-79$ years); 44 (51.8\%) patients were aged $<60$ years, and $41(48.2 \%)$ patients were aged $\geq 60$ years. We used D1, D2, 
Table 1 Patient and tumour characteristics at initial diagnosis

\begin{tabular}{|c|c|}
\hline Characteristics & Values (total $n=85$ ) \\
\hline \multicolumn{2}{|l|}{ Patient/tumor demographics } \\
\hline Age (years), median (range) & 59 (22 to 79$)$ \\
\hline Male sex, n (\%) & $48(56.5)$ \\
\hline $\begin{array}{l}\text { Median follow-up period (months), median } \\
\text { (range) }\end{array}$ & 27 (3 to 82 ) \\
\hline $\begin{array}{l}\text { Median survival time (months), median } \\
\text { (range) }\end{array}$ & 27 (2 to 82$)$ \\
\hline \multicolumn{2}{|l|}{ Tumor location, n (\%) } \\
\hline D1 & $16(18.8)$ \\
\hline D2 & $65(76.5)$ \\
\hline D3 & $3(3.5)$ \\
\hline D4 & $1(1.2)$ \\
\hline \multicolumn{2}{|l|}{ Operative procedure, n (\%) } \\
\hline Endoscopic resection & $8(9.4)$ \\
\hline Classic PD & $73(85.9)$ \\
\hline Partial duodenal resection & $1(1.2)$ \\
\hline Local tumor resection & $3(3.5)$ \\
\hline \multicolumn{2}{|l|}{ Pathologic features } \\
\hline \multicolumn{2}{|l|}{ Differentiation, n (\%) } \\
\hline Well & $20(23.5)$ \\
\hline Moderate & $51(60.0)$ \\
\hline Poor & $14(16.5)$ \\
\hline \multicolumn{2}{|l|}{ T stage, n (\%) } \\
\hline Tis & $4(4.7)$ \\
\hline T1a & $10(11.8)$ \\
\hline $\mathrm{T} 1 \mathrm{~b}$ & $4(4.7)$ \\
\hline T2 & $12(14.1)$ \\
\hline T3 & $19(22.3)$ \\
\hline $\mathrm{T} 4$ & $36(42.4)$ \\
\hline \multicolumn{2}{|l|}{ N stage, n (\%) } \\
\hline No & $52(61.2)$ \\
\hline $\mathrm{N} 1$ & $17(20.0)$ \\
\hline N2 & $16(16.8)$ \\
\hline \multicolumn{2}{|l|}{ M stage, n (\%) } \\
\hline MO & $88(100.0)$ \\
\hline M1 & $0(0.0)$ \\
\hline
\end{tabular}

Table 1 (continued)
Table 1 (continued)

\begin{tabular}{|c|c|}
\hline Characteristics & Values (total $n=85$ ) \\
\hline \multicolumn{2}{|l|}{ TNM stage, n (\%) } \\
\hline 0 & $4(4.7)$ \\
\hline I & $23(27.1)$ \\
\hline II & $25(29.4)$ \\
\hline III & $33(38.8)$ \\
\hline \multicolumn{2}{|l|}{ Common presenting symptoms, $\mathrm{n}(\%)$} \\
\hline Abdominal pain & $53(62.4)$ \\
\hline Jaundice & $35(41.2)$ \\
\hline Weight loss & $15(17.6)$ \\
\hline Vomiting & $11(12.9)$ \\
\hline Ro & $85(100.0)$ \\
\hline Median tumor diameter (cm), median (range) & 3.0 (0.8 to 8.3$)$ \\
\hline \multicolumn{2}{|c|}{$\begin{array}{l}\text { D1, the upper portion of duodenum; D2, the descending } \\
\text { portion of duodenum; D3, the horizontal portion of } \\
\text { duodenum; D4, the ascending portion of the duodenum; PD, } \\
\text { pancreaticoduodenectomy ; TNM stage, the TNM staging } \\
\text { of the tumors was based on the 8th edition of the American } \\
\text { Joint Committee on Cancer (AJCC) (in 2018); T stage, primary } \\
\text { tumor site; N stage, regional lymph node involvement; M stage, } \\
\text { presence or otherwise of distant metastasis spread; Tis, tumor } \\
\text { in situ; R0, no residue disease were observed under microscope } \\
\text { after srugical resection. }\end{array}$} \\
\hline
\end{tabular}

D3 and D4 to represent the upper portion, the descending portion, the horizontal portion and the ascending portion of the duodenum, and the incidence of each portion was $18.8 \%(16 / 85), 76.5 \%(65 / 85), 3.5 \%(3 / 85)$, and $1.2 \%$ $(1 / 85)$, respectively. Among the 85 patients, 1 (1.2\%) patient underwent partial duodenal resection, 3 (3.5\%) patients underwent local tumor resection, 8 (9.4\%) patients underwent endoscopic resection, and $73(85.9 \%)$ patients underwent Whipple surgery. The common presenting symptoms included abdominal pain $(62.4 \%, 53 / 85)$, jaundice $(41.2 \%, 35 / 85)$, weight loss $(17.6 \%, 15 / 85)$, and vomiting $(12.9 \%, 11 / 85)$. The details are provided in Table 1 .

\section{Pathological features}

We evaluated the $\mathrm{T}$ and $\mathrm{N}$ stages in detail according to the 8th edition AJCC staging system. In total, 4 (4.7\%) patients were in the Tis stage, 14 (16.5\%) patients were in the T1 stage, $12(14.1 \%)$ patients were in the T2 stage, $19(22.4 \%)$ 
Table 2 Lymph node characteristics

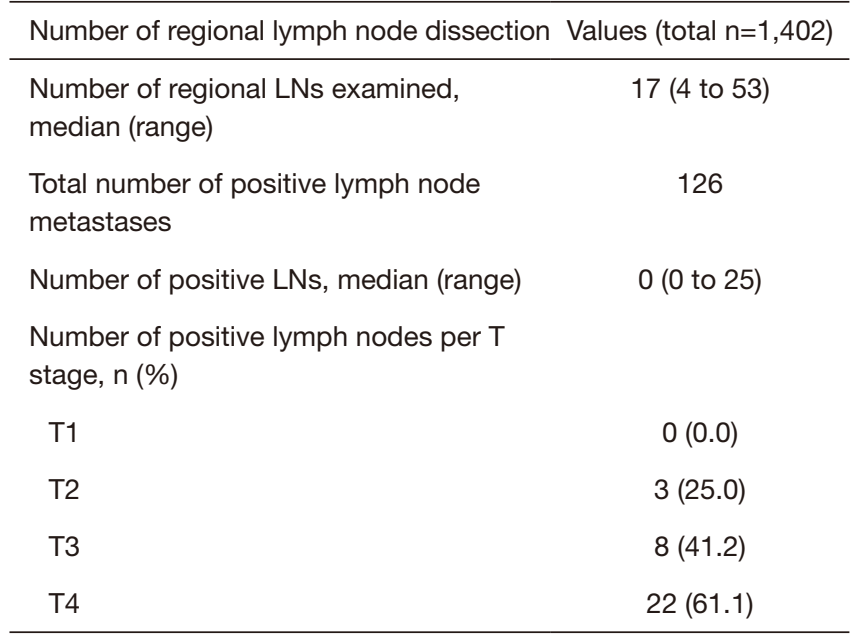

$\mathrm{N}$, number; LNs, lymph nodes; TNM stage, the TNM staging of the tumors was based on the 8th edition of the American Joint Committee on Cancer (AJCC) (in 2018); T stage, primary tumor site.

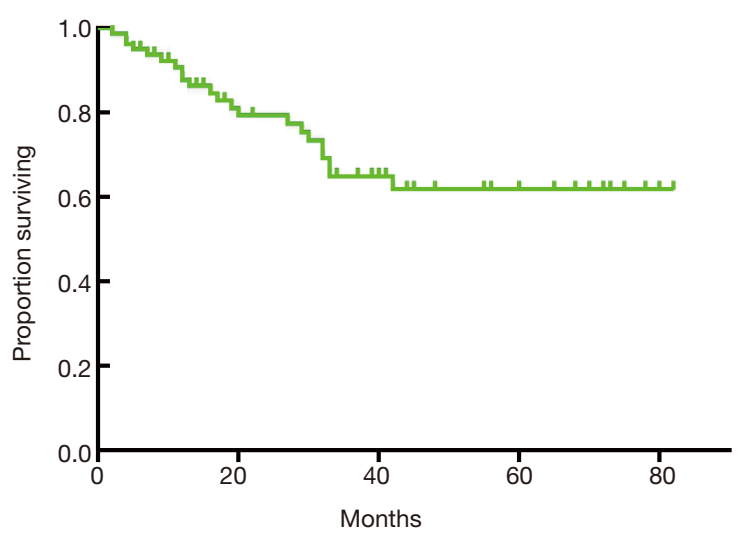

Figure 1 Overall survival after curative resection for our entire cohort including 85 patients with PDA. PDA, primary duodenal adenocarcinoma.

patients were in the T3 stage, and $36(42.4 \%)$ patients were in the T4 stage. The median tumor diameter was $3.0 \mathrm{~cm}$ (range, $0.8-8.3 \mathrm{~cm})$. In total, $20(23.5 \%)$ patients had welldifferentiated tumors, $51(60.0 \%)$ patients had moderately differentiated tumors, and $14(16.5 \%)$ patients had poorly differentiated tumors. In total, $50(58.8 \%)$ patients were in the N0 stage, 17 (20.0\%) patients were in the N1 stage, and $16(18.8 \%)$ patients were in the N2 stage. In general, except for the patients who underwent endoscopic resection and local tumor resection, 1,402 lymph nodes from 74 patients who underwent lymph node dissection were analyzed. The median number of lymph nodes dissected was 17 (range, 4-53). The total number of positive lymph node metastases was 126 , and the positive lymph node rate was $9.0 \%$ $(126 / 1,402)$. The positive lymph node rates of the patients with $\mathrm{T} 1, \mathrm{~T} 2, \mathrm{~T} 3$, and $\mathrm{T} 4$ tumors were $0 \%(0 / 7), 25.0 \%$ $(3 / 12), 42.1 \%(8 / 19)$, and $61.1 \%(22 / 36)$, respectively. There is a possibility that the deeper the tumor is, the more likely it is to metastasize through the lymph nodes. The details are provided in Tables 1,2.

\section{Prognostic factors for overall survival rate after surgical resection}

The median follow-up period was 27 months (range, 3-82 months), and the median survival time was 27.0 months (range, 2-82 months). The 1-, 3-, and 5 -year OS rates after RR were $93.7 \%, 79.4 \%$ and $64.9 \%$, respectively (Figure 1). The univariate analysis showed that the $\mathrm{N}$ stage $(\mathrm{P}<0.001)$, TNM stage $(\mathrm{P}=0.001)$, CA199 status (positive or negative) ( $\mathrm{P}=0.038)$, and lymph node positivity (LNP) $(\mathrm{P}=0.000)$ were related to $\mathrm{OS}$, and all these factors were related to worse outcomes (Table 3, Figure 2). Several studies previously reported that the higher the number of lymph node dissections, the better the OS (7,10-12). We divided these patients into 3 groups according to the median number of lymph nodes dissected. The number of lymph node dissections in group 1 was $\leq 5$, the number of lymph node dissections in group 2 was between 6 and 16, and the number of lymph node dissections in group 3 was $\geq 17$. However, we found that the number of total lymph nodes (TLN) retrieved was not associated with $\mathrm{OS}(\mathrm{P}=0.723)$. Then, we further analyzed the relationship between OS and the retrieved number of lymph nodes. We divided the patients into two groups according to the median number of lymph nodes and compared the prognosis of $\mathrm{N} 0$ and $\mathrm{N}+$ in the two groups but found no correlation $(\mathrm{P}=0.960)$. Additionally, we did not find any relationships between OS and tumor differentiation $(\mathrm{P}=0.136)$, $\mathrm{CEA}(\mathrm{P}=0.812)$, gender $(\mathrm{P}=0.477)$, operation type $(\mathrm{P}=0.860)$, tumor size $(\mathrm{P}=0.869)$, tumor site $(\mathrm{P}=0.120)$, age $(\mathrm{P}=0.733)$, intraoperative blood loss $(\mathrm{P}=0.660)$, or intraoperative blood transfusion $(\mathrm{P}=0.748)$ (Figure 2). These findings are inconsistent with those in previous research reports $(13,14)$. The $T$ stage and total operation time may have an effect on OS, and the $\mathrm{T}$ stage was associated with a poor OS $(\mathrm{P}=0.054)$. As mentioned above, the higher the $\mathrm{T}$ stage, the greater the positive rate 
Table 3 Univariate and Multivariate analysis for overall survival in patients with PDA

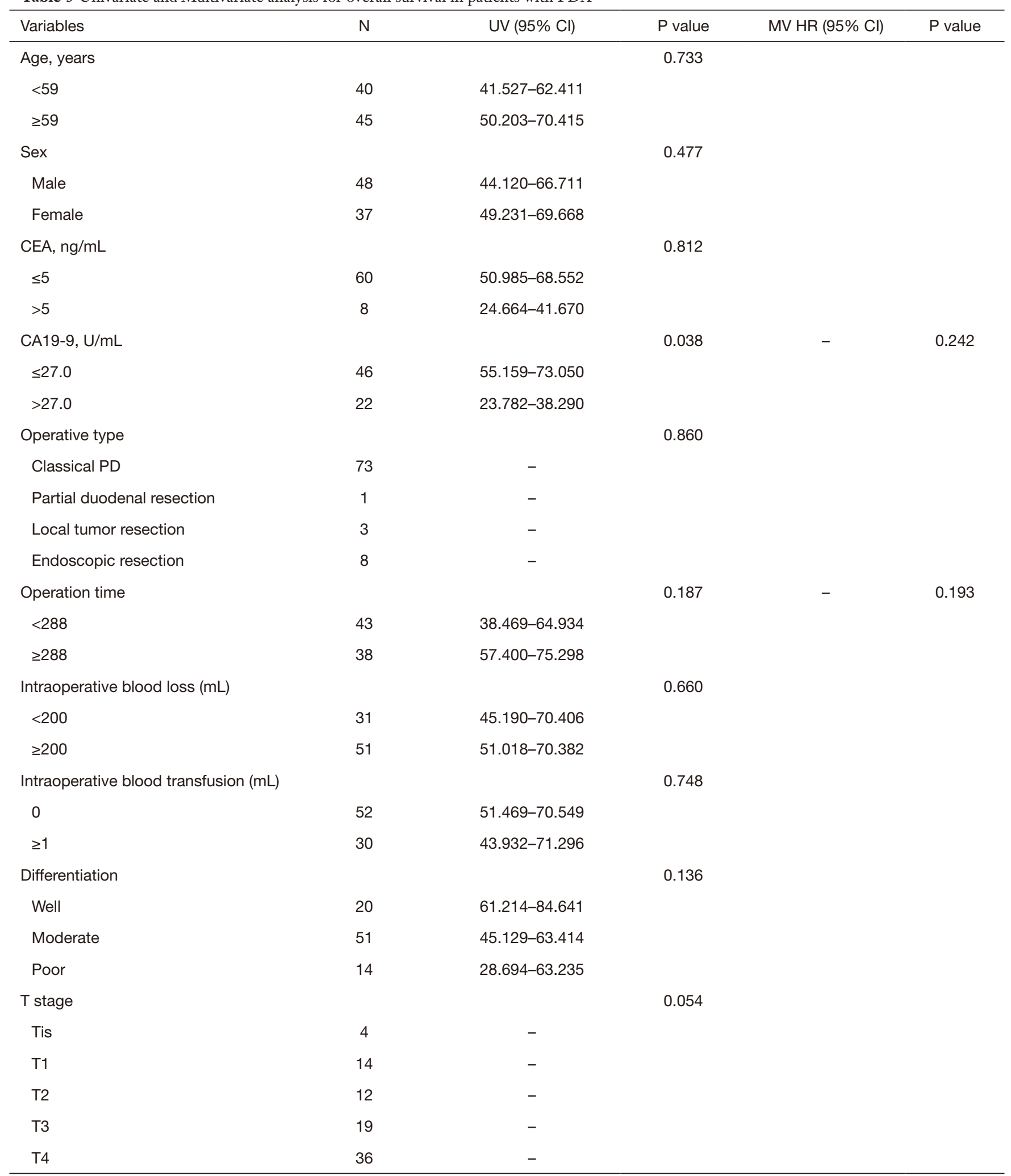

Table 3 (continued) 
Table 3 (continued)

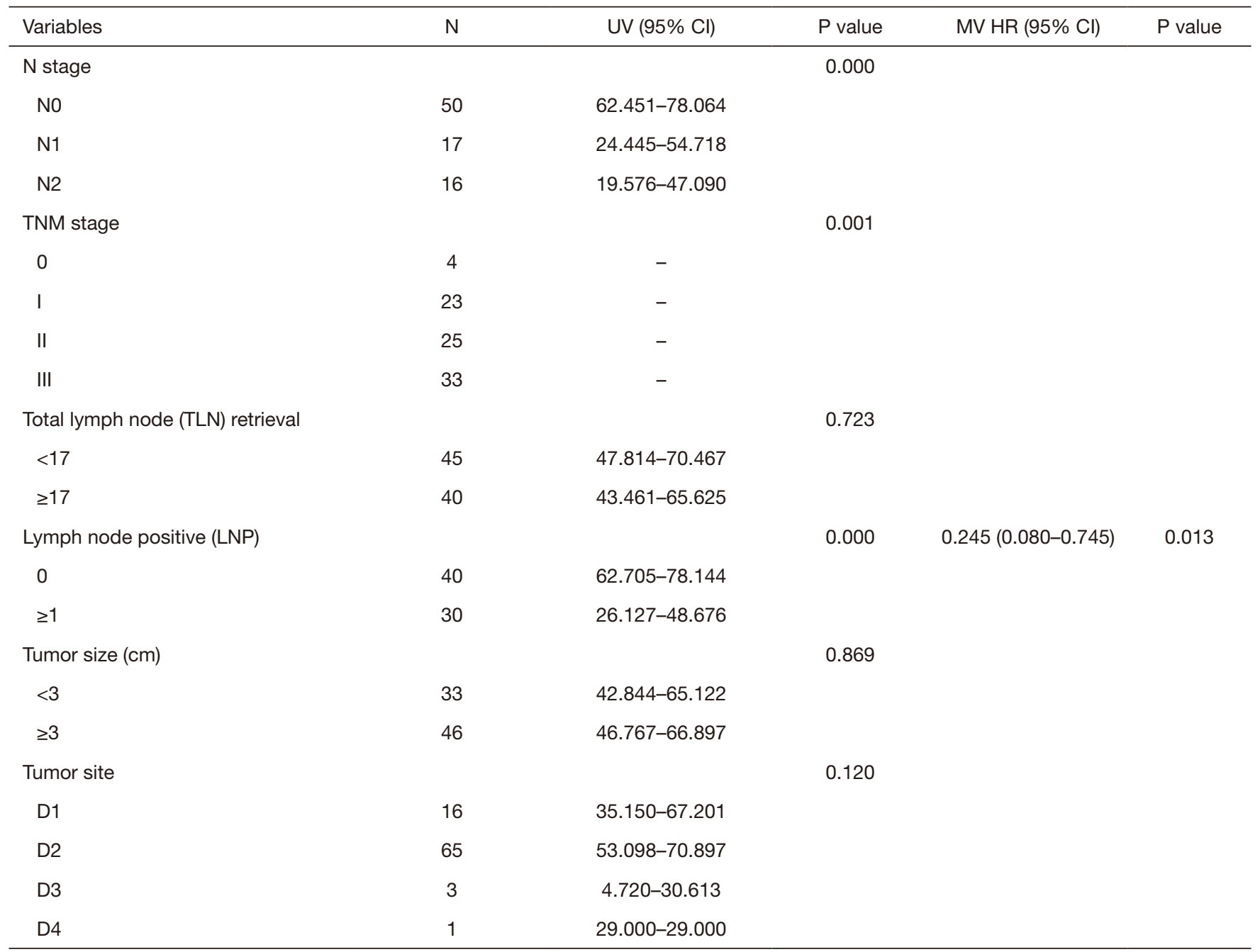

PDA, primary duodenal adenocarcinoma; N, number; UV, univariate analysis; Cl, confidence interval; MV, multivariate analysis; HR, hazard ratio; CEA, carcinoembryonic antigen; CA19-9, carbohydrate antigen 19-9; PD, pancreaticoduodenectomy; TNM stage, the TNM staging of the tumors was based on the 8th edition of the American Joint Committee on Cancer (AJCC) (in 2018); T stage, primary tumor site; N stage, regional lymph node involvement; $\mathrm{M}$ stage, presence or otherwise of distant metastasis spread; Tis, tumor in situ; TLN, total lymph node; LNP, lymph node positive; D1, the upper portion of duodenum; D2, the descending portion of duodenum; D3, the horizontal portion of duodenum; D4, the ascending portion of the duodenum.

of lymph node metastasis. We used a bivariate correlation analysis to compare the correlation between the $\mathrm{T}$ stage and $\mathrm{N}$ stage, and there was a high correlation between these two variables ( $\mathrm{r}=0.478, \mathrm{P}=0.01$ (sig. 2 -tailed). The length of the operation time was associated with a good OS $(\mathrm{P}=0.053)$ perhaps because more thorough surgical dissections require more time. We included the lymph node status, CA19-9 status, and length of operation time in the Cox regression model for the multifactor analysis, and the results suggested that the lymph node status is an independent risk factor for
OS (Table 3).

\section{Discussion}

In the previous literature, several studies reported the OS in PDA; Poultsides (7) reported that the OS rates at 5 years were $48 \%$ in their study. Lee (9) reported 3 - and 5 -year survival rates of $52.9 \%$ and $44.1 \%$, respectively. In Cloyd's (5) study, the median OS was 38 months following SR and 29 months following RR. The 5-year OS rates were 

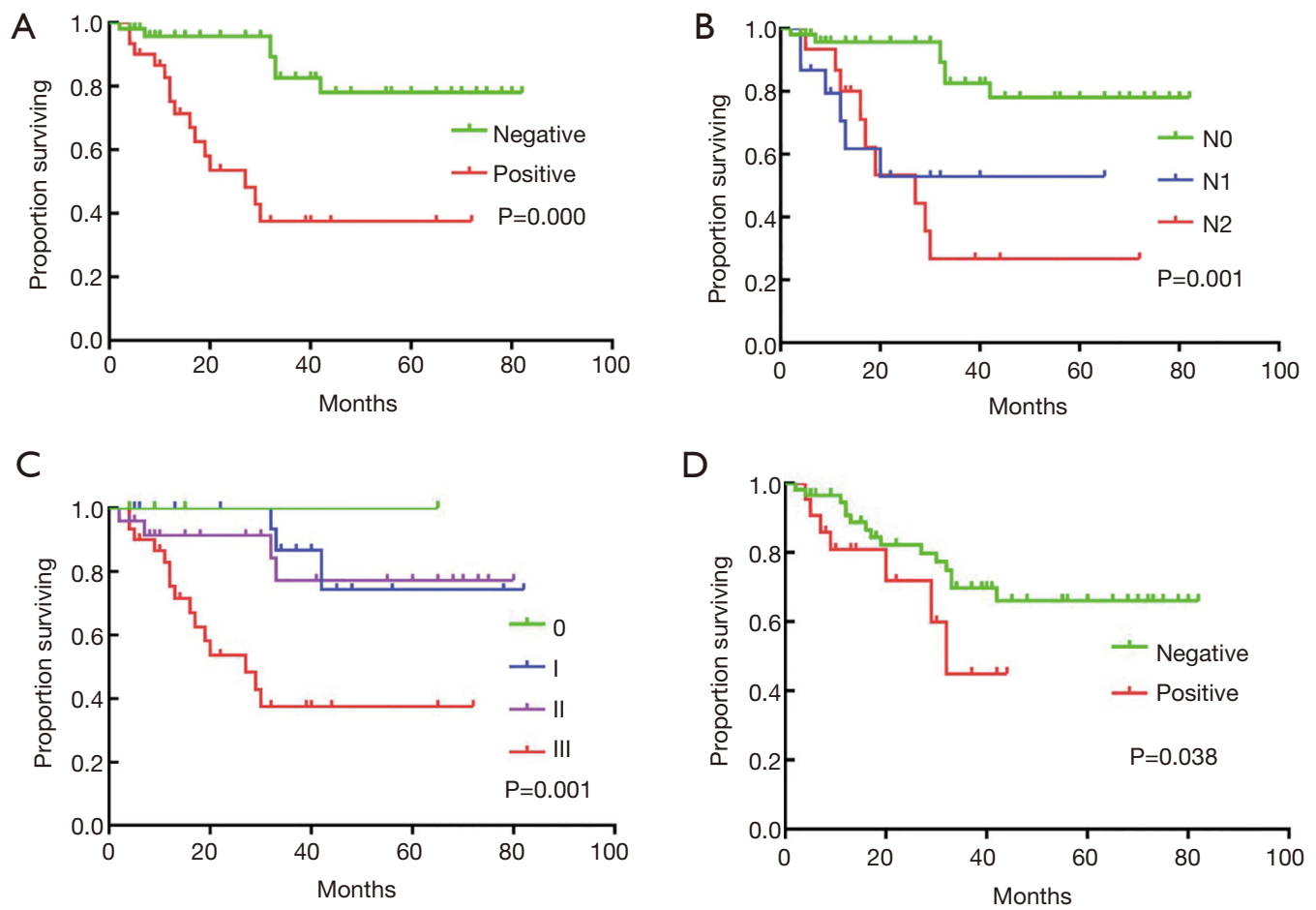

Figure 2 Risk factors associated with poor overall survival. (A) Lymph node status; (B) N stage; (C) TNM stage; (D) CA19-9 status. TNM stage, the TNM staging of the tumors was based on the 8th edition of the American Joint Committee on Cancer (AJCC) (in 2018); T stage, primary tumor site; N stage, regional lymph node involvement; M stage, presence or otherwise of distant metastasis spread; CA19-9, carbohydrate antigen.

41.3\% following SR and 37.6 following RR $(\mathrm{P}=0.89)$.

In our study, the median OS was 27 months (range, 2-82 months), and the 1-, 3-, and 5-year survival rates were $93.7 \%, 79.4 \%$, and $64.9 \%$, respectively. By using a univariate analysis, we found that the tumor site $(\mathrm{P}=0.120)$, tumor grade $(\mathrm{P}=0.136)$ and gender $(\mathrm{P}=0.477)$ were not independent prognostic factors. There was no significant difference in the survival rates among patients with different operation types $(\mathrm{P}=0.784)$. We failed to demonstrate that as the number of lymph node dissections increased, the patients' OS improved. However, we confirmed that lymph node positivity and the $\mathrm{N}$ stage were related to poor OS. As the lymph node positivity rate and $\mathrm{N}$ stage increased, the survival rate of the patients significantly decreased (the 5 -year OS of $\mathrm{pN} 0$ vs. $\mathrm{pN}+$ was $82.9 \%$ vs. $37.5 \%(\mathrm{P}=0.000)$, and the 5 -year OS of $\mathrm{pN} 0$ vs. $\mathrm{pN} 1$ vs. $\mathrm{pN} 2$ was $77.9 \%$ vs. $53.0 \%$ vs. $26.7 \%(\mathrm{P}=0.000)$, respectively). We also found that the TNM stage and CA19-9 status affected the survival of the patients. Our further research found that the $\mathrm{T}$ stage and $\mathrm{N}$ stage are correlated, suggesting that as the depth of tumor invasion increases, the probability of tumor metastasis through lymph nodes increases, and more attention should be paid to lymph node dissection. We further included the lymph node status, CA19-9 status, and length of operation in the Cox regression analysis and found that the lymph node status was the only independent influencing factor. Our research emphasizes the acquisition of positive lymph nodes rather than a mere increase in number, which is worthy of attention in future research.

Approximately $50 \%$ of small bowel adenocarcinomas occur in the duodenum, while the incidences in the jejunum and ileum are $30 \%$ and $20 \%$, respectively (15). Previous studies have shown that the prognosis of PDA is much worse than that of other small intestinal tumors $(16,17)$. Therefore, further studies investigating the prognostic factors of duodenal adenocarcinoma could help better guide clinical operations and improve the OS rate of patients.

Regarding PDA, pancreatoduodenectomy is the most common surgical method. However, different opinions exist, as Jordan et al. (5) found that when considering the surgery type, RR (defined as the removal of the primary site with a resection in continuity with other organs) was 
not associated with improved survival compared with SR (defined as the simple removal of the primary site) (5-year OS rates of $41.3 \%$ for SR vs. $37.6 \%$ for RR; $\mathrm{P}>0.05)$. Oka et al. (18) also reported a case series of early primary nonampullary DA; in their study, 13 of the 17 patients $(76.5 \%)$ treated by EMR had no severe complications or disease recurrence. Both Valli et al. (19) and Oka et al. (18) indicated that endoscopic resection appears to be a safe and efficient treatment for carefully selected patients with early primary nonampullary duodenal carcinoma. In our study, there was no significant difference in the survival rates among patients with different operation types $(\mathrm{P}=0.784)$ as mentioned above. Notably, in our study cohort, there were fewer patients with early-stage cancer (Tis, T1a disease) $(13.3 \%, 10 / 75)$ in the mucosa than other studies (4) likely because esophagoscopy and gastroduodenoscopy are not very popular in China, and many patients were in the middle and late stages of the disease when they were identified.

In Huang's (20) study, the authors attempted to determine the prognostic factors related to the OS time and the possible impact of obstructive jaundice (OJ) on survival. Cigarette smoking, cytology, the TNM stage, aspartate aminotransferase (AST), OJ, and cancer-directed surgeries (CDS) were significant factors related to OS in a univariate analysis. The independent predictors of long-term survival were CDS, the TNM stage, cytology, cigarette smoking, and AST using a Cox proportional hazards model. However, notably, the study cohort was very small and included only 23 patients. The mean follow-up time was 15.1 months, and the median OS was $5.9 \pm 2.5$ months. Both time spans were short, and there was no information regarding lymph node dissection since the TNM staging system changed during the past decades. Therefore, the credibility of this experimental conclusion is not high.

Several retrospective studies have indicated that other factors associated with a worse prognosis include poorly differentiated tumors, tumor location and the male gender (21). However, by using a univariate analysis, in our study, we found that the tumor site $(\mathrm{P}=0.120)$, tumor grade $(\mathrm{P}=0.136)$ and gender $(\mathrm{P}=0.477)$ were not independent prognostic factors likely because in our study, only one case was located in the ascending portion of the duodenum.

For lymphadenectomy, the 8th AJCC guidelines recommend at least six lymph nodes be excised and evaluated for the accurate $\mathrm{N}$ staging of duodenal or small bowel adenocarcinoma. Compared with the 7 th edition, $\mathrm{N} 1$ was redefined as one or two positive nodes, and N2 was redefined as more than two positive nodes. However, the optimal extent of resection and lymphadenectomy has not been well defined, and the ongoing debate has continued for many years (22).

Several single-institution, retrospective studies have demonstrated that lymph node involvement in surgical specimens has an adverse impact on survival $(2,4,6,7,9-12,17,23,24)$. Dabaja et al. (21) reported decreased survival in patients with nodal involvement compared with patients with no nodal involvement (median survival 22 vs. 78 months). Sarela et al. (10) demonstrated that the $\mathrm{pN}$ category was an independent significant adverse prognostic factor (5-year disease-specific survival: $\mathrm{pN}$, $83 \%$ vs. $\mathrm{pN}+, 56 \% ; \mathrm{P}=0.03)$. These authors believed that for duodenal adenocarcinoma, the number of lymph node dissections should be greater than 15; otherwise, the $\mathrm{N}$ stage may be reduced, resulting in a significant worsening in prognosis. Wilhelm et al. (11) conducted a populationbased propensity score-adjusted investigation of small bowel adenocarcinoma. Their study indicated an increased OS (HR 0.67, 95\% CI: 0.50-0.89, $\mathrm{P}<0.001$ ) and cancer-specific survival (HR 0.67, 95\% CI: 0.49-0.92, $\mathrm{P}=0.013$ ) in patients with $9+$ retrieved lymph nodes. Thus, these authors believed that at least 9 regional lymph nodes should be retrieved from adenocarcinoma of the small intestine to improve survival. However, in this study, the authors focused on patients with stage III small bowel adenocarcinoma, and there was no distinction among the duodenum, jejunum, and ileum. These studies highlight the importance of lymphadenectomy.

Numerous studies have shown that as the number of lymph node dissections increases, the long-term survival of patients simultaneously increases (25), but surgeons also need to simultaneously assess the possible increased perioperative risks, such as chyle leak, intestinal dysfunction, and mortality. Our research emphasizes the acquisition of positive lymph nodes rather than a mere increase in number, which could be worthy of attention in future research.

Several recent studies have also explored the impact of other factors on the survival of PDA patients $(14,20,26,27)$. Ecker et al. (27) compared the survival rates of patients treated with chemotherapy, radiotherapy, and surgery; however, interestingly, there was no difference in OS between the chemotherapy and combination chemoradiotherapy cohorts after surgical resection, thereby highlighting the importance of complete surgical extirpation in patients with locally aggressive tumors. A recent study by Wang et al. (26) using the SEER database found that marital 
status also has a significant impact on the OS of PDA patients and that married patients have significantly longer survival times than unmarried patients.

There are some risk conditions that may contribute to the development of PDA, such as hereditary polyposis syndromes, von Recklinghausen's disease, Lynch's syndrome, adult celiac disease, and Peutz-Jeghers syndrome $(14,28)$. However, due to research limitations, we could not fully include these factors. Furthermore, due to the limitations inherent in the retrospective nature of the study, it is inevitable that patients will be lost during follow-up, and it is difficult to ensure the integrity of the data. Our study is a single-center retrospective study with a small sample size, limiting the in-depth discussion of PDA. However, because PDA is a rare disease, designing randomized controlled experiments is time consuming and laborious and has low feasibility. Therefore, in the future, we may use more central data for in-depth research.

\section{Conclusions}

Despite all limitations, in our study the median OS was 27 months (range, 2-82 months), and the 5-year survival rates was $64.9 \%$. Our analysis suggests that the lymph node status is the only independent risk factor for OS. Simply increasing the number of lymph node dissections does not significantly improve the survival prognosis. Perhaps we should refer to the pattern of lymph node dissection in breast cancer and pay more attention to the strategy of positive lymph node detection.

\section{Acknowledgments}

Funding: This study was supported by the State Key Project on Infection Diseases of China (Grant No. 2017ZX10201021-007-003), the National The capital health research and development of special (No. 2018-14021), the National Natural Science Foundation of China (No. 81672461) and The CAMS Innovation Fund for Medical Sciences (CIFMS) (Grant No. 2017-12M-4-002).

\section{Footnote}

Reporting Checklist: The authors have completed the STROBE reporting checklist. Available at http://dx.doi. org/10.21037/apm-20-1280

Data Sharing Statement: Available at http://dx.doi. org/10.21037/apm-20-1280

Conflicts of Interest: All authors have completed the ICMJE uniform disclosure form (available at http://dx.doi. org/10.21037/apm-20-1280). The authors have no conflicts of interest to declare.

Ethical Statement: The authors are accountable for all aspects of the work in ensuring that questions related to the accuracy or integrity of any part of the work are appropriately investigated and resolved. The study was conducted in accordance with the Declaration of Helsinki (as revised in 2013). The study was approved by the Ethics Committee of the Cancer Hospital, Chinese Academy of Medical Sciences (ID: NCC2019C-016), and informed consent was taken from all the patients.

Open Access Statement: This is an Open Access article distributed in accordance with the Creative Commons Attribution-NonCommercial-NoDerivs 4.0 International License (CC BY-NC-ND 4.0), which permits the noncommercial replication and distribution of the article with the strict proviso that no changes or edits are made and the original work is properly cited (including links to both the formal publication through the relevant DOI and the license). See: https://creativecommons.org/licenses/by-nc-nd/4.0/.

\section{References}

1. Lu Y, Frobom R, Lagergren J. Incidence patterns of small bowel cancer in a population-based study in Sweden: increase in duodenal adenocarcinoma. Cancer Epidemiol 2012;36:e158-63.

2. Overman MJ, Hu CY, Kopetz S, et al. A population-based comparison of adenocarcinoma of the large and small intestine: insights into a rare disease. Ann Surg Oncol 2012;19:1439-45.

3. Locher C, Batumona B, Afchain P, et al. Small bowel adenocarcinoma: French intergroup clinical practice guidelines for diagnosis, treatments and follow-up (SNFGE, FFCD, GERCOR, UNICANCER, SFCD, SFED, SFRO). Dig Liver Dis 2018;50:15-9.

4. Sakamoto T, Saiura A, Ono Y, et al. Optimal Lymphadenectomy for Duodenal Adenocarcinoma: Does the Number Alone Matter? Ann Surg Oncol 2017;24:3368-75.

5. Cloyd JM, Norton JA, Visser BC, et al. Does the extent of resection impact survival for duodenal adenocarcinoma? 
Analysis of 1,611 cases. Ann Surg Oncol 2015;22:573-80.

6. Solaini L, Jamieson NB, Metcalfe M, et al. Outcome after surgical resection for duodenal adenocarcinoma in the UK. Br J Surg 2015;102:676-81.

7. Poultsides GA, Huang LC, Cameron JL, et al. Duodenal adenocarcinoma: clinicopathologic analysis and implications for treatment. Ann Surg Oncol 2012;19:1928-35.

8. Bakaeen FG, Murr MM, Sarr MG, et al. What prognostic factors are important in duodenal adenocarcinoma? Arch Surg 2000;135:635-41; discussion 641-2.

9. Lee HG, You DD, Paik KY, et al. Prognostic factors for primary duodenal adenocarcinoma. World J Surg 2008;32:2246-52.

10. Sarela AI, Brennan MF, Karpeh MS, et al. Adenocarcinoma of the duodenum: importance of accurate lymph node staging and similarity in outcome to gastric cancer. Ann Surg Oncol 2004;11:380-6.

11. Wilhelm A, Muller SA, Steffen T, et al. Patients with Adenocarcinoma of the Small Intestine with 9 or More Regional Lymph Nodes Retrieved Have a Higher Rate of Positive Lymph Nodes and Improved Survival. J Gastrointest Surg 2016;20:401-10.

12. Tran TB, Qadan M, Dua MM, et al. Prognostic relevance of lymph node ratio and total lymph node count for small bowel adenocarcinoma. Surgery 2015;158:486-93.

13. Bilimoria KY, Bentrem DJ, Wayne JD, et al. Small bowel cancer in the United States: changes in epidemiology, treatment, and survival over the last 20 years. Ann Surg 2009;249:63-71.

14. Zaaimi Y, Aparicio T, Laurent-Puig P, et al. Advanced small bowel adenocarcinoma: Molecular characteristics and therapeutic perspectives. Clin Res Hepatol Gastroenterol 2016;40:154-60.

15. Hatzaras I, Palesty JA, Abir F, et al. Small-bowel tumors: epidemiologic and clinical characteristics of 1260 cases from the connecticut tumor registry. Arch Surg 2007;142:229-35.

16. Falcone R, Romiti A, Filetti M, et al. Impact of tumor site on the prognosis of small bowel adenocarcinoma. Tumori 2019;105:524-8.

17. Wilhelm A, Galata C, Beutner U, et al. Duodenal localization is a negative predictor of survival after small bowel adenocarcinoma resection: A populationbased, propensity score-matched analysis. J Surg Oncol 2018;117:397-408.

18. Oka S, Tanaka S, Nagata S, et al. Clinicopathologic features and endoscopic resection of early primary nonampullary duodenal carcinoma. J Clin Gastroenterol 2003;37:381-6.

19. Valli PV, Mertens JC, Sonnenberg A, et al. Nonampullary Duodenal Adenomas Rarely Recur after Complete Endoscopic Resection: A Swiss Experience Including a Literature Review. Digestion 2017;96:149-57.

20. Hung FC, Kuo CM, Chuah SK, et al. Clinical analysis of primary duodenal adenocarcinoma: an 11-year experience. J Gastroenterol Hepatol 2007;22:724-8.

21. Dabaja BS, Suki D, Pro B, et al. Adenocarcinoma of the small bowel: presentation, prognostic factors, and outcome of 217 patients. Cancer 2004;101:518-26.

22. Overman MJ, Hu CY, Wolff RA, et al. Prognostic value of lymph node evaluation in small bowel adenocarcinoma: analysis of the surveillance, epidemiology, and end results database. Cancer 2010;116:5374-82.

23. Cloyd JM, George E, Visser BC. Duodenal adenocarcinoma: Advances in diagnosis and surgical management. World J Gastrointest Surg 2016;8:212-21.

24. Gibbs JF. Duodenal adenocarcinoma: is total lymph node sampling predictive of outcome? Ann Surg Oncol 2004;11:354-5.

25. Fleischmann I, Warschkow R, Beutner U, et al. Improved survival after retrieval of 12 or more regional lymph nodes in appendiceal cancer. Eur J Surg Oncol 2017;43:1876-85.

26. Wang N, Bu Q, Liu Q, et al. Effect of marital status on duodenal adenocarcinoma survival: A Surveillance Epidemiology and End Results population analysis. Oncol Lett 2019;18:1904-14.

27. Ecker BL, McMillan MT, Datta J, et al. Adjuvant chemotherapy versus chemoradiotherapy in the management of patients with surgically resected duodenal adenocarcinoma: A propensity score-matched analysis of a nationwide clinical oncology database. Cancer 2017;123:967-76.

28. Zhang S, Cui Y, Zhong B, et al. Clinicopathological characteristics and survival analysis of primary duodenal cancers: a 14-year experience in a tertiary centre in South China. Int J Colorectal Dis 2011;26:219-26.

Cite this article as: Li TY, Chen QC, Zhao H, Zhang YF, Zhao JJ, Cai JQ. Prognostic factors for overall survival in patients with primary duodenal adenocarcinoma. Ann Palliat Med 2021;10(3):2781-2790. doi: 10.21037/apm-20-1280 